\section{ABSTRACT}

Teacher trainers are currently faced with the task of designing consultation programs for special education teachers. To make these programs contemporary, effective, and relevant for trainees, decisions about their design are best based upon careful examination of a broad range of factors. Three such factors are discussed: (a) characteristics of consultation, including existing consultation models applicable to special education situations; (b) practitioner needs for consultation information; and (c) specific consultation skills to include in the training sequence. Information related to each factor is presented in terms of possible alternatives for training program design, and trainers are urged to base consultation program development on a broad perspective of the consultation field.

Few would dispute the fact that consultation has become an integral component of the job of special education teachers, especially for those who instruct mildly handicapped students. Almost from the beginning of widespread mainstreaming, professionals in the field have emphasized the necessity of classroom teacherspecial education teacher collaboration (e.g., Adelman, 1972; Bauer, 1975; Lilly, 1971; McKenzie et al., 1970). This sentiment continues to be expressed (e.g., Lilly \& Givens-Ogle, 1981; Miller \& Sabatino, 1978; Powell, 1982; Spodek, 1982) and is echoed by special education practitioners (Evans, 1980; Friend, 1982; Haight \& Molitor, 1983). School districts' inclusion of consultation as a responsibility in teachers' formal job descriptions has helped to establish the legitimacy of the role (Friend \& McNutt, 1985).

Because consultation has become so important in special educators' jobs, many teachertraining institutions are developing programs to prepare teachers to function as consultants. To maximize these programs' effectiveness, a number of factors of program design should be considered. This paper explicates three such factors: (a) contemporary knowledge about the characteristics of consultation, (b) practitioner needs for information about consultation, and (c) data on the efficacy of specific consultation skills. The first factor is included because it represents the scope of the content a training program may include, while the second is included because of the importance of addressing practitioner concerns during training. The third factor
TESE; $1985,8(3), 115-120$

\title{
Training Special Educators to be Consultants
}

\section{Considerations for Developing Programs}

\section{Marilyn Friend}

Marilyn Friend is an Assistant Professor in the College of Education of the University of Oklahoma at Norman. 
is the basis on which accountable programs are developed; accordingly, its presentation seems especially critical.

Because the intent of this discussion is to suggest a number of alternatives related to each factor and to increase trainers' awareness of the possible consequences of their adoption, a broad perspective of consultation will be espoused. This approach reflects a particular view of the task we face: We have been given a challenging opportunity to design innovative programs that could have far-reaching impact on special education practitioners and on the nature of service delivery systems for mildly handicapped learners. Because the task is so important, we should proceed with caution, and caution suggests that at this point we do not have enough information about consultation as it applies to special education teachers to justify eliminating any of the training alternatives. If we fail to examine the entire range of options available for consultation practice, we run the risk of omitting potentially valuable approaches from our programs and of unnecessarily limiting the skills of teacher trainees.

\section{CHARACTERISTICS OF CONSULTATION}

The entire focus of a consultation training program is influenced by the way in which consultation is conceptualized. Two components contribute to this conceptualization: the definition of consultation and consultation models.

\section{Definitions}

The term consultation has acquired such a variety of definitions that teacher trainers developing programs should first determine the meaning it will have for them. Generally, definitions fall along a continuum from specific to general. For example, some educators define consultation as a set of interactions between a professional with expertise in a specific area and a consultee (i.e., teacher) through which a student indirectly benefits (e.g., Fine \& Tyler, 1971; Reschly, 1976). Others consider it to be any type of supportive relationship between school professionals (e.g., Alpert, 1982; Conoley \& Conoley, 1982).

In special education, most definitions mention collaborative relationships; that is, the consultant and classroom teacher are assumed to bring equivalent levels of expertise to the interactions. However, the definitions vary consider- ably in terms of who is considered the primary consultee. Idol-Maestas (1983) specifies that consultation is any support given to classroom teachers to help them teach mildly handicapped learners, while Cohen (1982) broadens that definition to include administrators and other school staff as potential consultees. Hawisher and Calhoun (1978) and Ravin, Arntzen, and Peery (1982) mention interactions with parents in their definitions and also include students as potential consultees.

Clearly, the definition given to consultation will determine to a major extent the scope of the training program. If teacher trainers select a definition focusing on special education teacher-classroom teacher interactions, training can be fairly specific because the types of consulting situations addressed will be limited. If counselors, administrators, and other school staff are also given substantial attention in the definition, additional skills training will be necessary. If parents are included, trainers add yet another set of skills and also risk becoming involved in issues of content ownership, since there already are programs in parent training in many institutions. The notion of training teachers through a consultation program to better manage interactions with students further complicates the situation. While many teacher trainees would benefit from such training, this topic might be considered by some professionals to fall within the domain of counseling.

In general, it seems as though a set of advantages and drawbacks should be weighed in deciding the most appropriate definition of consultation for any specific training program. Selecting a narrow definition will allow trainers to concentrate their efforts on producing teachers who are expert in interacting with certain groups of adults in the school setting. However, that choice also entails the risk of leaving teachers largely unprepared to deal with other groups. If a more inclusive definition of consultation is adopted, trainees will be familiar with a far broader range of potential situations in which consultative skills are required, but the depth of their knowledge may be limited.

\section{Consultation Models}

Selecting models to guide consultation practice is an important step in the process of deciding the scope of a planned training program. A number of consultation models have already been explicated in other disciplines (e.g., school psychology, community psychology, counsel- 
ing, business), and these might be useful in designing special education training.

Gallessich (1982) identifies the following as general models: mental health, clinical, organization, behavioral, program, and education and training. While it is beyond the scope of this paper to detail the many characteristics of each of these, it can be said that they differ from one another in terms of problem formulation, methods employed in consulting, consultant assumptions about change, and consultant values orientation (Gallessich, 1982). Because of these differences, the models that teacher trainers choose will have a significant impact on the topics and skills included as training content. For example, in the behavioral model (Bergan, 1977), a problem is viewed as resulting from a consultee's lack of expertise, intervention is conceptualized as using principles of reinforcement to increase desired and decrease undesired consultee behaviors, and emphasis is placed on data collection and analysis. Selecting a behavioral model to guide a training program, then, necessitates content stressing the formulation of problems in observable terms, strategies for modifying behavior, and techniques for collecting, recording, and reporting data.

Alternatively, in an organizational model (Schmuck, Runkel, Arends, \& Arends, 1977), problems are conceptualized within the context of the school environment, intervention is multidimensional and encourages schoolwide participation, and human relations are stressed. Based on these characteristics, training would include an understanding of schools as social systems and how change can be effected in them, decision-making and communication skills, and interpersonal problem solving.

In special education consultation, the limited information available on both training programs and practice reflects a behavioral orientation (Heron \& Harris, 1982; Idol-Maestas, 1983; Knight, Meyers, Paolucci-Whitcomb, Hasazi, \& Nevin, 1981; Lew, Mesch, \& Lates, 1982). This is not surprising, since the behavioral model lends itself more readily than the others to clear specification of skills for training sequences and evaluation of training results. However, the field of special education consultation is so new that we would be remiss if we ignored the potential contributions of alternative models. The task for teacher trainers is to determine the extent to which existing consultation models (in addition to the behavioral model) are applicable to spe- cial education consultation and how to adapt them to accommodate the unique characteristics of special education teachers functioning as consultants.

The careful selection and use of appropriate consultation models will have two major benefits for trainees. First, special education teachers (and perhaps trainers, too) will avoid the pitfall (Gallessich, 1982) of trying to consult atheoretically, a practice that generally leads to less than satisfactory results. Second, by using a variety of models for training, teachers will have a repertoire of approaches from which to choose, giving them the flexibility necessary to successfully manage a wide range of consulting situations.

\section{PRACTITIONER NEEDS FOR CONSULTATION INFORMATION}

While those involved in training special education personnel should help shape the practices used in the schools, they also have an obligation to be responsive to the training needs felt by practitioners. In the area of special education consultation, this implies that the design of training programs should address immediate concerns of special education teachers about their interactions with other school professionals and demonstrated gaps in their knowledge of how to be successful consultants.

\section{Teacher Perceptions of Consulting Skill}

Teachers' perceptions of their consulting skill are one indicator of practitioners' needs; several studies of this topic have been reported in the literature. Evans (1977) interviewed resource teachers who indicated they felt that they should consult more than they did, but that they lacked the training needed to do so. Specific consulting skills the teachers felt they needed were not mentioned.

Friend (1984) presented special educators and classroom teachers with a list of 17 specific consultation skills relating to interpersonal communication (e.g., probing, paraphrasing, conflict resolution, steps in interpersonal problem solving, interviewing, and observation). She found that resource teachers perceived all the mentioned skills as essential to their jobs. They also indicated that they were moderately skilled in the specified areas, though their responses suggested some need for training in conducting inservice activities, employing a planned se- 
quence for interpersonal problem solving, and using interpersonal communication techniques. It is also interesting that the classroom teachers in this study rated the resource teachers as signficantly less skilled as consultants than the resource teachers rated themselves.

Haight and Molitor (1983) asked their sample of teachers with Michigan's special education teacher consultant certificate to evaluate their confidence in their ability to consult. The authors reported that the consultants were confident of their skills in some areas, but also mentioned needing additional training in public relations, human relations, counseling, and inservice training.

These data on special educators' perceptions indicate that our knowledge base in this area is inadequate for informed decision making. They suggest that teachers have some skills, but provide little guidance in identifying in which specific consulting techniques practitioners feel a need for training. If practitioners' perceptions of their need for consultation skills are to be considered in the design of training programs, teacher trainers should encourage further study of this area. This is an aspect of special education consultation in which the alternatives have not as yet even been identified.

\section{Teacher Performance in Consulting}

Another element to consider in examining special educators' needs in consultation is their performance as consultants. The data on this topic come exclusively from the behavioral model, usually in case study form. For example, Idol-Maestas (1983) and Egner and Lates (1975) described their consulting-training programs and provided samples of trainee data collection projects to demonstrate the skills acquired in carrying out behavior change programs. The data for mainstreamed learners indicated that the consultation efforts had had a positive effect on achievement. No studies could be located examining special educators' interaction skills.

As was true of special educators' perceptions of their consulting skills, the dearth of information on how special education teachers complete their consulting responsibilities indicates that we are not yet able to develop this component of training programs on the basis of known practitioner need. Our alternatives are to minimize the importance of this factor and proceed with our training programs, or to attempt to find out what special education consultants are doing in their schools, in order to create relevant training. A danger in not seeking the information is that trainers' judgments about practitioner needs may become the sole determinant of training content; as a result, very real needs may remain unaddressed.

\section{SKILLS FOR CONSULTATION TRAINING PROGRAMS}

More consultation skills have been identified by professionals in various disciplines than most special education training programs can possibly include. A list of frequently mentioned skills might include interpersonal problem solving, interviewing, conflict resolution, management of resistance, observation, data collection, following through on interactions, paraphrasing, empathic listening, nonverbal communication, giving and receiving feedback, decision making, time management, inservice training, contracting, and negotiation. Because this list is only a partial list and because major segments of courses or even entire courses could be devoted to many of the skills, teacher trainers' decisions on which to emphasize and which to eliminate will be difficult.

To a certain extent, the model(s) selected assist in determining skill content. For example, as mentioned earlier, adopting a primarily behavioral model necessitates focusing on observation and data collection. However, many of the process skills in consultation, that is, those which address how to actually conduct interactions, are applicable across models. Thus the dilemma of skill selection cannot be entirely resolved by selecting particular consultation models.

Alternative considerations for the selection of skills to include in training are the extent to which consulting skills are amenable to training and the existance of evidence that training does improve performance. The field of school psychology offers relevant data. Bergan and Tombari (1976) reported that school psychologist consultants who successfully completed the problem identification phase of the problemsolving process were in every instance able to assist their consultees in resolving the problem. Consultants who failed to accurately identify the problem never reached the point of intervening. White and Fine (1976), in studying consulta- 
tive situations with and without follow-ups, found that classroom teachers' perceptions of the school psychologist consultants and target students were more favorable when at least two interactions followed the initial one. In special education, Safran and Barcikowski (1984) found that the content of the statements of special education consultants about students significantly affected classroom teachers' perceptions of those students.

Unfortunately, evaluating the effectiveness of specific consultation skills is a relatively recent concern for all disciplines training consultants; and so while we have many alternatives among skills to include in training programs, choices can be based only on professionals' judgments. A firmer basis for these decisions would be data from systematic investigations of consulting skills. As teacher trainers introduce skills into their consultation programs, they can contribute to the knowledge needed for decision making by reporting which skills improve trainee performance as consultants. Especially needed is knowledge pertaining to the interaction skills.

\section{CONCLUSION}

It is readily acknowledged that the factors just presented by no means exhaust those which teacher trainers should address as they design consultation programs. Issues concerning the similarities and differences between preservice and inservice consultation training have not been considered, nor has there been mention of how to incorporate consultation programs into already crowded special education training curricula. An exploration of training needs unique to teachers who consult fulltime versus those germane to teachers who also provide direct instruction to students has likewise been omitted. Perhaps most critical for developing programs, attention has not been given to establishing criteria by which to evaluate special education consultation training programs.

Despite these omissions, the challenge presented to teacher trainers remains clear: to prepare teachers to establish and maintain successful professional relationships with the adults in schools in order to facilitate mildly handicapped students' success in mainstream settings. Meeting that challenge requires atten- tion by professionals to numerous factors that may affect program design.

\section{Suggestions for Research}

The process of developing effective teachertraining programs in consultation will be facilitated by the availability of research data. Four areas on which researchers' efforts should be focused can be identified. First, additional information is needed on the state of the art of consultation as it is currently practiced in schools. Both quantitative and qualitative data about how special education teachers meet their consultative responsibilities would be valuable in considering training approaches.

This type of research would provide a broad picture of special education consultation. A second avenue of inquiry, examining specific variables in consultative interactions, could contribute a more detailed analysis of the consultation process. For example, studies of the types of verbal exchanges occurring during interactions, the individuals with whom special educators most frequently consult, and the decisions reached through consultation could assist teacher trainers to develop programs that address the most relevant process skills. That research could also enable trainers to more appropriately sensitize trainees to personal characteristics influencing consultation.

A third research area concerns intervention. Study is needed of the skills hypothesized as valuable for special education consultants, both in terms of specifying efficient and effective training practices and documenting increases in trainee skill levels. By examining this area, trainers will be able to develop accountable programs that produce teacher consultants with high competency levels.

Finally, research is needed on the impact of training on practice. Changes in special education consultants' behaviors as a result of training should be studied in field settings. In addition, longitudinal data combining information about special educators' competency to carry out the consultation process with data on mainstreamed students' achievement could enhance already available knowledge of the impact of consultation programs on handicapped learners.

The task facing us is enormous, and it cannot be completed quickly or easily. Other disciplines in which consultation has been studied (psychology, for example) can provide guidance 
for our own exploration, but we must also strive to create consultation training programs tailored to address the needs of special educators and the mainstreamed students they serve. By being receptive to the wide range of alternatives that might influence our consultation practice, we can accomplish our goal.

\section{REFERENCES}

Adelman, H.S. (1972). The resource concept-Bigger than a room. Journal of Special Education, 6, 361-367.

Alpert, J.L. (Ed.). (1982). Psychological consultation in educational settings. San Francisco: JosseyBass.

Bauer, H. (1975). The resource teacher-A teacher consultant. Academic Therapy, 10, 299-304.

Bergan, J.R. (1977). Behavioral consultation. Columbus, $\mathrm{OH}$ : Charles E. Merrill.

Bergan, J.R., \& Tombari, M. (1976). Consultant skill and efficiency and the implementation and outcomes of consultation. Journal of School Psychology, 14, 3-14.

Cohen, J.H. (1982). Handbook of resource room teach ing. Rockville, MD: Aspen.

Conoley, J.C., \& Conoley, C.W. (1982). School consultation, A guide to training and practice. New York: Pergamon Press.

Egner, A., \& Lates, B.J. (1975). The Vermont Consulting Teacher program: Case presentation. In C. Parker (Ed.), Psychological consultation: Help. ing teachers meet special needs (pp. 31-53). Minneapolis: University of Minnesota, Leadership Training Instifute.

Evans, S.B. (1977). The consultant role of the resource teacher (Doctoral dissertation, University of Arizona, 1977). Dissertation Abstracts International, 37, 2701A.

Evans, S.B. (1980). The consulting role of the resource teacher. Exceptional Children, 46, 402-404.

Fine, M.J., \& Tyler, M.M. (1971). Concerns and directions in teacher consultation. Journal of School Psychology, 9, 436-444.

Friend, M. (1982). Consultation in resource teaching (Doctoral dissertation, Indiana University, 1981). Dissertation Abstracts International, 42, 5085A5086A.

Friend, M. (1984). Consulting skills for resource teachers. Learning Disability Quarterly, 7, 246-250.

Friend, M., \& McNutt, G. (1985). A comparative study of resource teacher job descriptions and perceptions of resource teacher responsibilities. Manuscript submitted for publication.
Gallessich, J. (1982). The profession and practice of consultation. San Francisco: Jossey-Bass.

Haight, S.L., \& Molitor, D.I. (1983). A survey of special education teacher consultants. Exceptional Children, 49, 550-553.

Hawisher, M.F., \& Calhoun, M.L. (1978). The resource room. Columbus, $\mathrm{OH}$ : Charles $\mathrm{E}$. Merrill.

Heron, T.E., \& Harris, K.C. (1982). The educationalconsultant: Helping professionals, parents, and mainstreamed students. Boston: Allyn \& Bacon.

Idol-Maestas, L. (1983). Special educator's consultation handbook. Rockville, MD: Aspen.

Knight, M.F., Meyers, H.W., Paolucci-Whitcomb, P., Hasazi, S.E., \& Nevin, A. (1981). A four year evaluation of consulting teacher service. Behavioral Disorders, 6, 92-100.

Lew, M., Mesch, D., \& Lates, B.J. (1982). The Simmons College generic consulting teacher program: A program description and data based applications. Teacher Education and Special Education, $5(2), 11-16$.

Lilly, S.M. (1971). A training based model for special education. Exceptional Children, 37, 745-749.

Lilly, M.S., \& Givens-Ogle, L.B. (1981). Teacher consultation: Present, past, and future. Behavioral Disorders, 6, 73-77.

McKenzie, H.S., Egner, A.N., Knight, M.F., Perelman, P.F., Schneider, B.M., \& Garvin, J.S. (1970). Training consulting teachers to assist elementary teachers in the management and education of handicapped children. Exceptional Children, 37 , 137-143.

Miller, T.L., \& Sabatino, D.A. (1978). An evaluation of the teacher consultant model as an approach to mainstreaming. Exceptional Children, 45, 86-91.

Powell, T.H. (1982). Mainstreaming: A case for the consulting teacher. Journal for Special Educa tors, 17, 183-188.

Ravin, L.A., Arntzen, L.S., \& Peery, B. (1982). A practical approach to RSP: A handbook for the Resource Specialist Program. Springfield, IL: Charles C Thomas.

Reschly, D.J. (1976). School psychology consultation: Frenzied, faddish, or fundamental? Journal of School Psychology, 14, 105-113.

Safran, S.P., \& Barcikowski, R.S. (1984). LD consultant information in mainstreaming: Help or hindrance? Learning Disability Quarterly, 7, 102-107.

Schmuck, R.A., Runkel, P.J., Arends, J.H., \& Arends, R.I. (1977). The second handbook of organization development in schools. Eugene: University of Oregon, The Center for Educational Policy and Management.

Spodek, B. (1982). What special educators need to know about regular classrooms. Educational Forum, 46, 295-307.

White, P.O., \& Fine, M.J. (1976). The effects of three schools' consultation modes on selected teacher and pupil outcomes. Psychology in the Schools, 13, 414-420. 